\title{
Análise da Fragilidade Ambiental da Bacia Hidrográfica à Montante do Reservatório de Ernestina/RS
}

\section{Analysis of the Environmental Fragility of the Hydrographic Basin Upstream of the Reservoir Ernestina/RS}

Ramiro Pereira Bisognin * Patrícia Ziani **

Carine Baggiotto ***

Gabriel Fernandes ****

Rafael Cabral Cruz *****

\section{Resumo:}

A matriz energética brasileira é dependente de aproveitamentos hidrelétricos que se caracterizam como atividades de alto impacto ambiental. Entretanto, esses aproveitamentos também estão sujeitos a impactos circunvizinhos que podem reduzir seu potencial de geração de energia. Nesse sentido, o presente estudo objetivou analisar a fragilidade ambiental do reservatório da Usina Hidrelétrica de Ernestina/RS. Para tanto, foi elaborado mapa conceitual relacionado à fragilidade do lago, e elencadas variáveis do objeto de estudo. Destas, cinco foram selecionadas com base na relevância, disponibilidade e qualidade dos dados. Para cada variável elaborou-se um mapa, e atribuíram-se notas e pesos. Em seguida foi realizada a álgebra pelo Software ArcGIS 10.3® (ESRI), sendo atribuídas notas iguais para todas as variáveis. Como resultado obteve-se o mapa de fragilidade ambiental, pelo qual se constatou que a área de estudo pode ser classificada, predominantemente, como de fragilidade média. Outro aspecto relevante é que a zona de fragilidade muita alta ficou, basicamente, restrita ao entorno do reservatório de Ernestina. Assim, ratifica-se que o estudo de fragilidades ambientais pode ser considerado uma ferramenta oportuna para diagnóstico das perturbações tanto para o empreendimento quanto para os municípios envolvidos por meio do planejamento e gestão dessa área.

\section{Abstract:}

The Brazilian energy matrix is dependent on hydroelectric projects that are characterized as activities of high environmental impact. However, such uses are also subject to surrounding impacts that may reduce their potential for power generation. In this sense, the present study aimed to analyze the environmental fragility of the reservoir of the Ernestina / RS Hydroelectric Power Plant. For this, a conceptual map was elaborated related to the fragility of the lake, and the variable variables of the object of study. Of these, five were selected based on their relevance, availability and data quality. For each variable a map was drawn, and scores and weights were assigned. Algebra was then performed by ArcGIS 10.3® Software (ESRI), with equal scores being assigned to all variables. As a result, the map of environmental fragility was obtained, whereby it was found that the study area can be classified, predominantly, as medium fragility. Another relevant aspect is that the zone of very high fragility was basically restricted to the surroundings of the reservoir of Ernestina. Thus, it is confirmed that the study of environmental fragilities can be considered as a timely tool for diagnosis of disturbances both for the enterprise and for the municipalities involved through the planning and management of this area.

Engenheiro Ambiental. Doutorando do Programa de Pós-Graduação em Engenharia Civil - Recursos Hídricos e Saneamento Ambiental pela UFSM. professor na UERGS, Unidade Três Passos.

** Doutoranda em Geografia pelo PPGGEO-UFSM

*** Mestre em Engenharia Ambiental pela UFSM

**** Engenheiro Ambiental e Sanitarista pela UFSM

Dr. em Ecologia pela UFRGS. Professor Associado da Fundação Universidade Federal do Pampa (UNIPAMPA)- Campi de São Gabriel

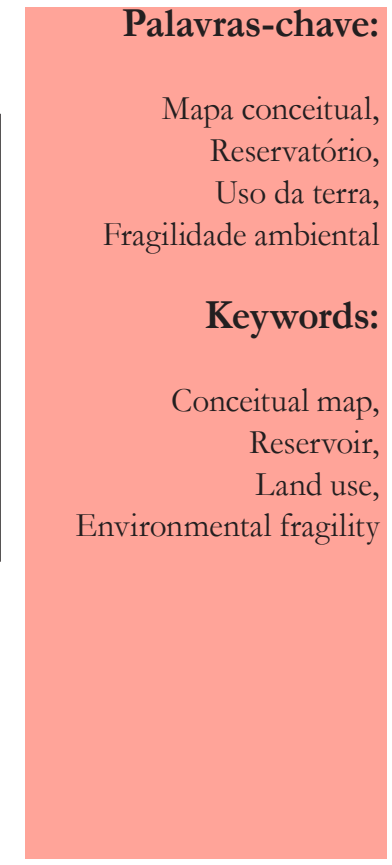




\section{INTRODUÇÃO}

$\mathrm{O}_{\mathrm{s}}^{\mathrm{h}}$ Brasil é um país com grande potencial de uso dos recursos hídricos para fins de geração de energia elétrica, sendo a hidráulica responsável por $63,88 \%$ da capacidade instalada de geração de energia (ANEEL, 2018). Porém, ao utilizar o potencial dos rios para gerar energia, muitas são as modificações que o homem faz no meio ambiente. Uma das maiores modificações se refere aos barramentos dos cursos d'água, os quais originam impactos ambientais negativos na fauna, flora e no meio socioeconômico da região em que são implantados.

Nesse sentido, por impacto ambiental entendem-se as alterações das propriedades físicas, químicas, biológicas do meio ambiente, sejam elas positivas ou negativas, causadas por qualquer forma de matéria ou energia resultante das atividades humanas que afetem diretamente ou indiretamente a saúde, a segurança, e o bem estar da população; as atividades sociais e econômicas; a biota; as condições estéticas e sanitárias ambientais e; a qualidade dos recursos ambientais (BRASIL, 1986).

A fim de auxiliar a tomada de decisão quanto à viabilidade ambiental da instalação de futuros empreendimentos, ou mesmo para identificar os aspectos com potencial efeito danoso a empreendimentos em operação, como abordado nesta pesquisa, a análise de fragilidades ambientais é considerada importante ferramenta de auxílio, que permite indicar áreas de menor ou maior fragilidade em relação a determinados regimes de perturbações (DONHA et al., 2006; TAMIOSSO, 2011).

Em estudos de fragilidade ambiental são necessários conhecimentos básicos sobre aspectos físicos do ambiente, tais como relevo, solo, geologia, clima, uso da terra e cobertura vegetal para os procedimentos operacionais. Estas informações ao serem analisadas de maneira integrada, por meio de tecnologias de Sensoriamento Remoto e Sistemas de Informação Geográfica (SIG), resultam em um produto cartográfico que expressa diferentes graus de fragilidade que o ambiente possui em função de suas características (KAWAKUBO et al., 2005; DONHA et al., 2006), além de que a modelagem cartográfica permite identificar e analisar estruturas das paisagens de forma clara e objetiva (CAVALCANTI, 2014; MELO, 2016).

De acordo com Ghezzi (2003), identificar a fragilidade ambiental de bacias hidrográficas por meio de análises isoladas de indicadores de aspectos físicos relevantes do ambiente, seguido do cruzamento destes, indica a in- tensidade com que este ambiente pode ser explorado sem prejudicar sua estabilidade, considerando, ainda, as limitações a ele impostas através dos componentes naturais e ações antrópicas.

Segundo Brasil (2010), qualquer perturbação dos padrões e processos em uma bacia hidrográfica que possa provocar degradações na qualidade ambiental, pode ser considerado fragilidade. As fragilidades ambientais são mensuradas na forma de notas atribuídas para variáveis indicadoras dos processos, que podem ser mapeadas na escala de estudo. Estas notas permitem identificar as áreas de maior ou menor sensibilidade às perturbações, de modo a contribuir para o entendimento da realidade espacial e auxiliar na tomada de decisão quanto às potencialidades e limitações da área de estudo (DONHA et al., 2006; BRASIL, 2010).

Neste contexto, mapas conceituais se apresentam como recurso relevante na análise de fragilidades ambientais, principalmente na identificação e seleção das variáveis indicadoras dos processos físicos. Segundo Novak e Cañas (2008), mapas conceituais consistem em ferramenta organizadora e representativa do conhecimento. Enquanto que para para Tavares (2007), os mapas conceituais possibilitam a estruturação do conhecimento sobre determinado assunto, permitindo ao(s) autor(es) visualizar(em) e analisar(em) o tema em profundidade e extensão.

Apesar dos aproveitamentos hidrelétricos causarem várias interferências no ambiente natural, tais como: alterações quali-quantitativa dos recursos hídricos, de habitats, hidrologia, conservação da vegetação, hábitos culturais, entre outros, uma vez constatada a viabilidade técnica, econômica e ambiental de um empreendimento, após sua implantação é imprescindível o zelo de sua estrutura física para manter-se em operação o máximo possível, evitando assim a construção de novos empreendimentos como esse.

Nesse sentido, este estudo objetivou analisar a fragilidade ambiental da bacia hidrográfica a montante do reservatório da Usina Hidrelétrica Ernestina/RS frente a ações que possam reduzir a qualidade da água do lago, sua capacidade de armazenamento e, por conseguinte, o potencial de geração de energia elétrica. Portanto, a presente pesquisa apresenta a caracterização da área de estudo, análises das variáveis uso da terra, cargas poluidoras ao reservatório, resistência a impactos ambientais, declividade, vulnerabilidade natural do aquífero a contaminação e por fim, a fragilidade ambiental da bacia hidrográfica a montante do reservatório. 


\section{MATERIAIS E MÉTODOS}

\subsection{Caracterização da área de estudo}

A UHE de Ernestina, administrada pela Companhia Estadual de Geração e Transmissão de Energia Elétrica (CEEE-GT), está em operação desde agosto de 1957, e é o primeiro aproveitamento hidrelétrico do rio Jacuí, em relação a sua nascente, cujo licenciamento ambiental foi regularizado em 2001, junto à Fundação Estadual de Proteção Ambiental Henrique Luiz Roessler (FEPAM). Essa UHE possui reservatório de regularização anual de 38,50 $\mathrm{km}^{2}$, composto por uma barragem do tipo concreto protendido com $13 \mathrm{~m}$ de altura e $400 \mathrm{~m}$ de comprimento, equipada com unidade geradora com turbina do tipo Francis e potência efetiva de 3,7 MW (ENGEPLUS, 2012).

A UHE Ernestina localiza-se na porção norte do Estado do Rio Grande do Sul (RS). Situa-se na Bacia Hidrográfica do Alto Jacuí, a qual se caracteriza por ser uma das principais bacias hidrográficas de domínio estadual. O reservatório insere-se nos municípios de Ernestina, Marau, Nicolau Vergueiro, Tio Hugo e Ibirapuitã. Contudo, a bacia hidrográfica de captação do reservatório ainda contem- pla parte do território dos municípios de Passo Fundo e Mato Castelhano, com área total de $1048 \mathrm{~km}^{2}$ (Figura 1).

A região do entorno do reservatório caracteriza-se por apresentar núcleos de ocupação residencial, matas, pastagens e plantações. Em função do tipo de solo ocorrente no local, isto é, Latossolos, profundos, bem drenados, muito porosos e bem estruturados, observa-se elevada aptidão agrícola na região quando corrigida sua fertilidade, com predomínio de lavouras de soja, trigo e milho, bem como a prática da pecuária. $\mathrm{O}$ relevo em condições suave ondulado corrobora para esta aptidão agropecuária.

Além disso, o reservatório de Ernestina encontra-se sobre aquífero fraturado, formado por rochas vulcânicas básicas e intermediárias mesozóicas, denominado Sistema Aquífero Serra Geral I. Quanto ao substrato rochoso, tanto o reservatório como o barramento da UHE Ernestina, localizam-se sobre rochas que compõem a Bacia do Paraná, que consiste em sucessivos derrames de lavas vulcânicas intermitentes com intercalação de rochas sedimentares (CPRM, 2005).

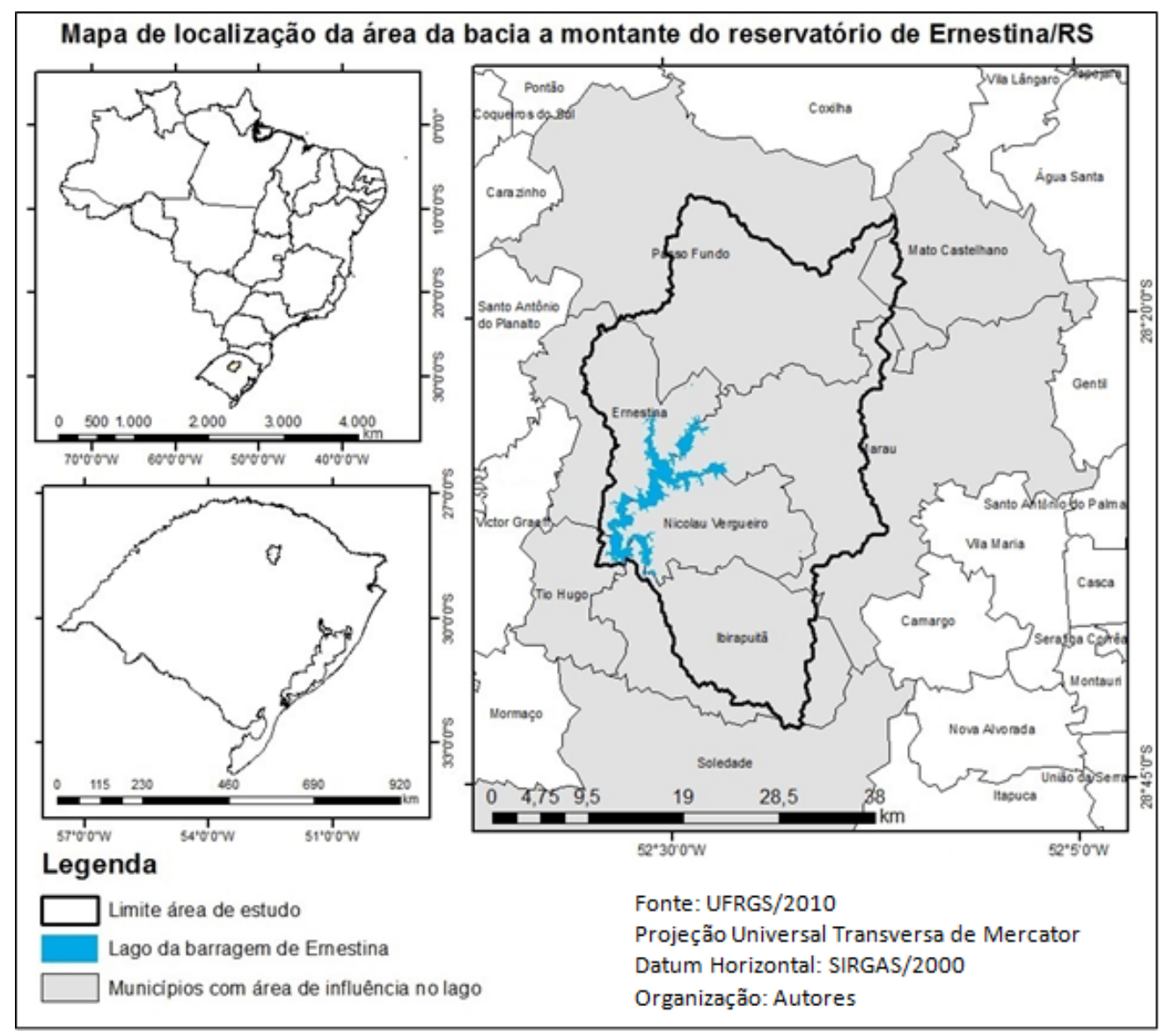

Figura 1 - Mapa de localização da área de estudo Fonte: : Elaboração dos autores 


\subsection{Análise de variáveis e elaboração de mapas}

A identificação, seleção e análise das fragilidades ambientais da bacia hidrográfica a montante do reservatório da UHE Ernestina foi realizada, inicialmente, a partir da elaboração de um mapa conceitual (Figura 2) no software CmapTools, versão 6.01, onde foram discutidos, por equipe interdisciplinar composta por engenheiros ambientais, geógrafos, agrônomo e oceanógrafo, aspectos relevantes referentes ao empreendimento.

A Figura 2 apresenta o reservatório no topo da análise para atender a demanda de energia elétrica pelo ser humano que busca, constantemente, a melhoria da qualidade de vida. Nesse processo, ações antrópicas, aliadas a eventos climáticos e as características ambientais de uma região, podem interferir ou intensificar o regime de perturbações sobre uma área, tornando-a frágil a determinados eventos. Os fatores, potencialmente perturbadores a qualidade e quantidade de água do reservatório da UHE Ernestina, foram explorados no mapa conceitual para identificar possíveis perdas de geração de energia elétrica por alterações no nível d'água e de suas propriedades físicas, químicas e biológicas.

Com base no mapa conceitual, foram definidas as variáveis indicadoras dos processos relacionados à qualidade do meio ambiente na escala de estudo, descartando variáveis abstratas como recomendado por Melo (2016). A essas variáveis foram atribuídas notas, as quais foram cruzadas a fim de se identificar os locais do reservatório mais suscetíveis a perturbações causadas pelo meio antrópico na bacia hidrográfica em questão.

Para cada variável foram elaborados mapas temáticos, no software ArcGIS 10.3® (ESRI), utilizando tanto a base cartográfica disponibilizada pela Universidade Federal do Rio Grande do Sul (UFRGS), com escala 1:50.000, quanto os arquivos digitais para uso em SIG disponibilizados pela FEPAM com base cartográfica na escala de 1:250.000. Em seguida, por meio da interpolação das variáveis, foram gerados produtos cartográficos temáticos com os resultados obtidos, como recomenda-

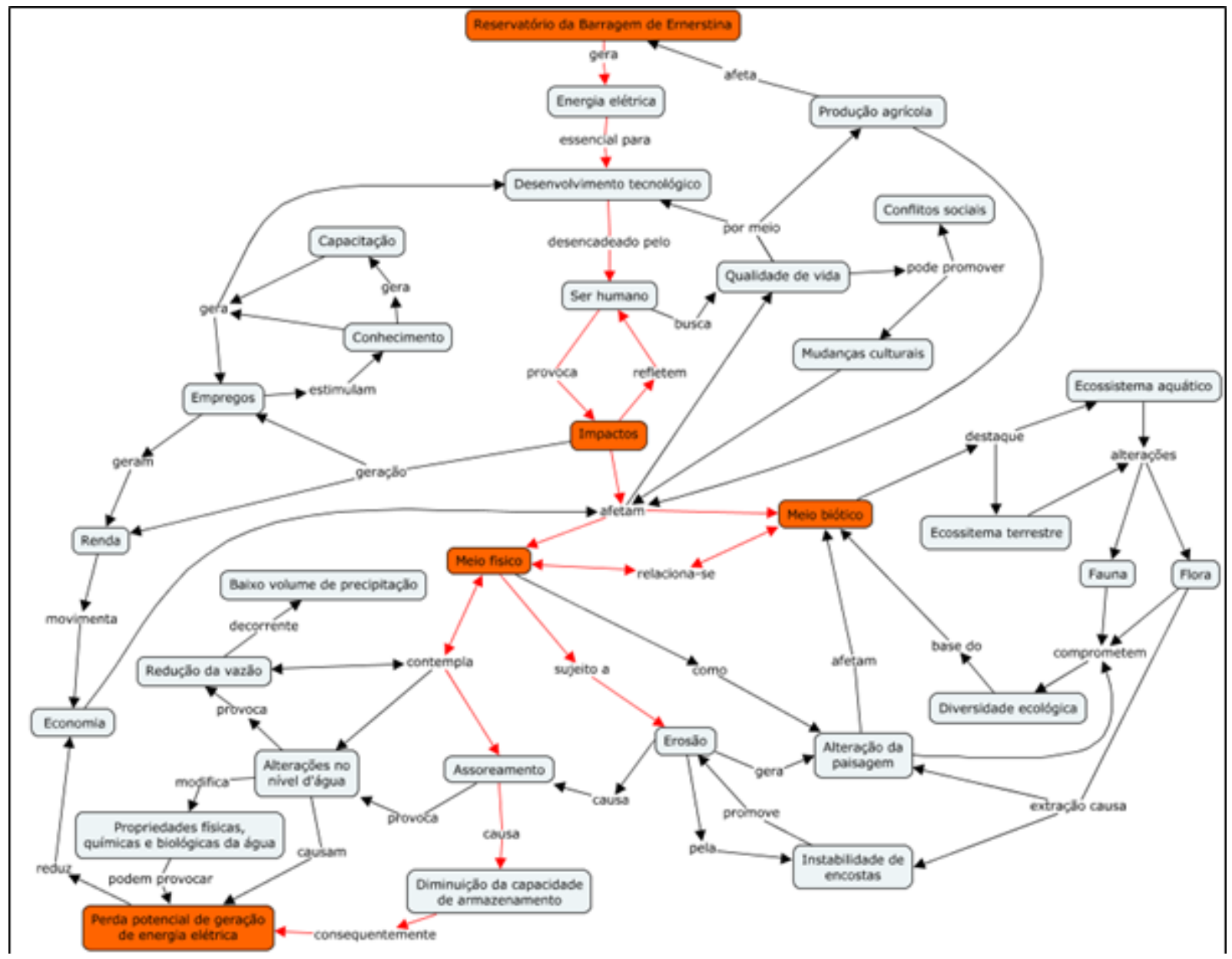

Figura 2 - Fluxograma elaborado para a definição das variáveis de fragilidade ambiental Fonte: : Elaboração dos autores 
do por Melo (2016).

Entre os mapas confeccionados estão: mapa de localização, mapa de uso da terra, mapa das cargas poluidoras, mapa pedológico, mapa de declividade, mapa de vulnerabilidade natural do aquífero à contaminação e, por fim, o mapa de fragilidade ambiental.

Para cada um destes mapas foram atribuídas notas dentro de suas respectivas classes pré-estabelecidas, baseados na literatura, que serão detalhados a seguir individualmente. Em relação aos mapas, salienta-se que todos foram elaborados no sistema de coordenadas SIRGAS 2000 - UTM - Zone 22 Sul, e, por fim, foram reclassificados e transformados para Raster com resolução espacial de $30 \mathrm{~m}$.

\subsection{Variável uso e ocupação da terra}

O mapa de uso da terra foi elaborado a partir da imagem Landsat 5 TM datada de 04 de novembro de 2011. O método de classificação utilizado foi supervisionado por meio da Máxima Verossimilhança (Maxver). Deste modo, identificaram-se as seguintes classes de uso da terra: mancha urbana, água, floresta, lavoura, solo exposto e campo.

As variáveis analisadas foram classificadas, com base em Ross (1994), em graus diferenciados conforme a fragilidade de cobertura vegetal e uso da terra (Tabela 1).

Tabela 1 - Peso das variáveis do mapa de uso da terra no entorno do reservatório de Ernestina/RS

\begin{tabular}{ccc}
\hline Tipo de uso da terra & Classe de Fragilidade & Nota \\
\hline Mancha urbana & Extremamente alta & 1 \\
Solo Exposto & Muito alta & 50 \\
Lavoura & Alta & 100 \\
Campo & Médio & 150 \\
Floresta & Baixa & 200 \\
Água & Muito baixa & 255 \\
\hline Fonte: : Adaptado de ROSS (19)4) &
\end{tabular}

\subsection{Variável potencial de cargas poluidoras ao re- servatório}

Para o mapa de cargas, os dados de DBO (Demanda Bioquímica de Oxigênio), NTK (Nitrogênio Total Kjeldahl), P (Fósforo) e Coliformes Termotolerantes foram obtidos do Relatório Síntese do Planejamento dos Usos da Água na Bacia Hidrográfica do Alto Jacuí - Etapas A e B (ENGEPLUS, 2012).

Assim, confeccionaram-se 4 mapas e somaram-se todos, resultando no mapa de cargas totais. Os valores foram escalonados conforme a regra: quanto maior é a carga, maior a fragilidade. A maior carga recebeu valor
1 (maior fragilidade) e a menor carga, 255 (menor fragilidade) (BRASIL, 2010). O mapa resultante é o mapa de fragilidades relativo ao potencial de contaminação orgânica, o qual aborda cargas pontuais e difusas como lançamentos de efluentes domésticos e industriais, resíduos sólidos e aplicação de dejetos animais e fertilizantes nas lavouras. A classificação proposta com base em BRASIL (2010) está apresentada na Tabela 2.

Tabela 2 - Classificação da variável cargas poluidoras ao reservatório de Ernestina/RS

\begin{tabular}{ccc}
\hline Variável & Classe de Fragilidade & Nota \\
\hline & Muito alta & 1 \\
Cargas poluidoras & Média & 64 \\
& Baixa & 127 \\
& Muito baixa & 191 \\
& & 255 \\
\hline
\end{tabular}

Fonte: : Adaptado de BRASIL (2010)

\subsection{Variável resistência a impactos ambientais quan- to ao tipo de solo}

Os dados de classificação dos tipos de solos quanto à resistência a impactos ambientais, disponibilizados pela FEPAM (2001), foram utilizados para identificação dos solos da bacia hidrográfica quanto à classe de fragilidade (Tabela 3).

Tabela 3 - Classificação dos tipos de solo* no entorno do reservatório de Ernestina/RS, quanto à resistência a impactos ambientais

\begin{tabular}{cccc}
\hline $\begin{array}{c}\text { Tipo de Solo } \\
\text { (Sigla) }\end{array}$ & $\begin{array}{c}\text { Classe de } \\
\text { Resistência a } \\
\text { impactos Ambientais }\end{array}$ & $\begin{array}{c}\text { Classe de } \\
\text { Fragilidade }\end{array}$ & Nota \\
\hline Lvaf - Rle & B/C & Muito Alta & 1 \\
MTf - RLe & C & Média & 128 \\
PVA 3 - R & B & Baixa & 192 \\
NVdf 1 & A & Muito Baixa & 255 \\
LVd 3 & A & Muito Baixa & 255 \\
LVaf & A & Muito Baixa & 255 \\
\hline
\end{tabular}

Fonte: : Adaptado FEPAM (2001).

* Compõem a área de estudo os solos dos tipos: Latossolo Vermelho Distrófico Típico (LVd 3), Latossolo Vermelho Alumino férrico Típico - NeossoloLitólico (Lvaf - Rle), Nitossolo Vermelho DistroférricoLatossólico (NVdf 1), ChernossoloArgilúvico Férrico Típico NeossoloLitólico (MTf - RLe), Latossolo Vermelho Alumino férrico Típico (LVaf), Argissolo Vermelho Amarelo Alumínico Típico - Neossolo Litólico (PVA 3 - R)

\subsection{Variável declividade}

O mapa de declividade foi obtido a partir do processamento de dados do SRTM (Shuttle Radar TopographyMission - NASA) e os intervalos das classes de declividade foram adaptados de Ross (1994) e Padilha (2008) onde para classes de declividade menores que $6 \%$ foi atribuído nota de 255 e classificado como muito fraco, 
entre 6 e $12 \%$ nota 191 classificado como fraco, entre 12 e $20 \%$ nota 127 classificado como médio, entre 20 e $30 \%$ nota 64 classificado como forte e para declividade maior que $30 \%$ foi dada nota 1 caracterizada como fragilidade muito forte (Tabela 4).

Tabela 4 - Notas das classes de fragilidade de declividade no entorno do reservatório de Ernestina/RS

\begin{tabular}{ccc}
\hline Classes de declividade (\%) & Classe de Fragilidade & Nota \\
\hline$>30$ & Muito Forte & 1 \\
20 a 30 & Forte & 64 \\
12 a 20 & Médio & 127 \\
6 a 12 & Fraco & 191 \\
$<6$ & Muito Fraco & 255 \\
\hline
\end{tabular}

Fonte: : Adaptado de ROSS (1994)

\subsection{Variável vulnerabilidade natural do aquífero à contaminação}

Para a determinação da vulnerabilidade natural do aquífero à contaminação foi utilizado o sistema GOD, descrito por Foster et al. (2006). Este sistema analisa os parâmetros: G (Grau de confinamento hidráulico da água subterrânea/aquífero); O (Ocorrência de estratos de cobertura) e D (Profundidade/distância até o lençol freático ou o teto do aquífero confinado). Os dados foram obtidos do Sistema de Informações de Águas Subterrâneas (SIAGAS), em 2015 (http:// siagasweb.cprm. gov.br/layout/). Assim, foi gerado banco de dados com informações relativas aos parâmetros de cada captação por poço tubular e/ou escavado, como: coordenadas geográficas, nível estático, perfis geológicos e grau de confinamento do aquífero.

Foster et al. (2006) descreve o método GOD com classes de vulnerabilidade que variam de $<0,1$, entre 0,1 e 0,3 e entre 0,3 e 0,5, assim foi adaptado o método atribuindo nota de 255 caracterizada como baixa para vulnerabilidade menor que 0,1,127 e média fragilidade para vulnerabilidade entre 0,1 e 0,3 e 1 para alta fragilidade variando entre 0,3 e 0,5 vulnerabilidade. Essa adaptação foi necessária para atribuir a mesma escala em todas as variáveis.

Tabela 5 - Classificação da vulnerabilidade e fragilidade à contaminação do aquífero na bacia hidrográfica a montante do reservatório de Ernestina/RS

\begin{tabular}{ccc}
\hline Classes de vulnerabilidade & Classe de Fragilidade & Nota \\
\hline $0,3-0,5$ & Alta & 1 \\
$0,1-0,3$ & Média & 127 \\
$<0,1$ & Baixa & 255
\end{tabular}

\subsection{Fragilidade ambiental}

Esta pesquisa atribuiu peso a cada uma das variáveis apresentadas na Tabela 6 , levando em consideração a influência de cada na fragilidade do reservatório, de modo que a somatória desses pesos resultasse em 1.

Tabela 6 - Peso das variáveis para elaboração do mapa de fragilidade ambiental da bacia hidrográfica a montante do reservatório de Ernestina/RS

\begin{tabular}{cc}
\hline Variável & Peso atribuído \\
\hline Uso da terra & 0,2 \\
Cargas poluidoras & 0,2 \\
Resistência a impactos pelo tipo de solo & 0,2 \\
Declividade & 0,2 \\
Vulnerabilidade a contaminaçāo & 0,2 \\
\hline
\end{tabular}

Fonte: Organização dos autores (2017)

De acordo com os pesos selecionados, foi efetuada a combinação linear ponderada dos mapas (Equação 1). Foram utilizados pesos iguais para todas as variáveis, pois não houveram diferenças significativas nos resultados que justificassem distinção de pesos.

\section{Equação 1}

Fragilidade $=(($ Uso da terra*0,2) $+($ Cargas*0,2) $+($ Resistência a impactos pelo tipo de Solo*0,2) + (Declividade*0,2) $+($ Vulnerabilidade*0,2)).

\section{RESULTADOS E DISCUSSÃO}

A partir da reflexão dos conceitos e do estudo das interações pertinentes ao reservatório da UHE Ernestina, exploradas no fluxograma (Figura 2), foram definidas as variáveis uso daterra, potencial de cargas poluidoras ao reservatório, resistência a impactos quanto ao tipo de solos, declividade e vulnerabilidade natural do aquífero à contaminação como indicadoras dos processos relacionados à qualidade ambiental na escala de estudo, devendo, portanto, serem investigadas para a determinação das fragilidades ambientais frente a perturbações.

O estudo contemplou a análise e interpretação de todas as informações referentes às frações/porções contribuintes à bacia hidrográfica do Reservatório de Ernestina, uma vez que, em pesquisas ambientais, os locais e os fenômenos são fatores importantes para determinar as correlações entre eles, haja vista que as distribuições espaciais das ocorrências não são independentes, como descrevem Melo et al. (2016). 


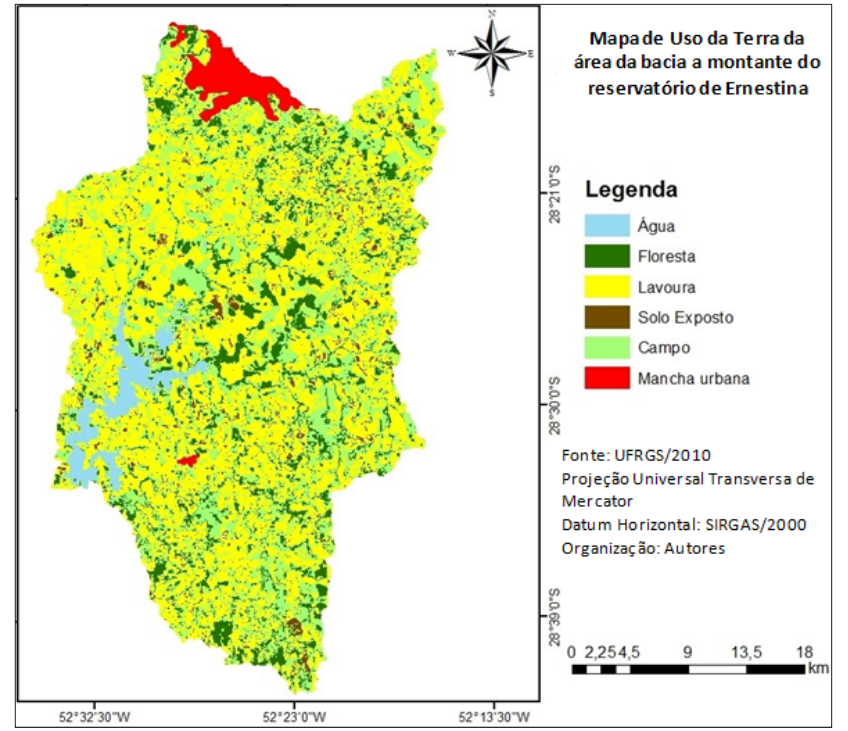

Figura 3 - Mapa de uso da terra da bacia a montante do reservatório de Ernestina/RS

Fonte: : Elaboração dos autores

\subsection{Variável uso da terra}

No mapa de uso da terra da bacia hidrográfica a montante do reservatório de Ernestina (Figura 3) é possível perceber como ocorre a distribuição dos diferentes tipos de uso da terra no decorrer da área de estudo. Nesse mapa (Figura 3), pode-se observar a predominância de lavouras, onde se destacam as plantações de soja, arroz, trigo e milho. Essas plantações, por sua vez, carecem de significativas retiradas de água para a sua irrigação, principalmente soja e arroz, e, de modo geral, acabam ocasionando maior aporte de sedimentos aos cursos d'água que, consequentemente, contribuem para o assoreamento e diminuição da profundidade destes, comprometendo assim os diversos usos.

Quanto as áreas de campo observadas, destaca-se que as mesmas estão associadas principalmente as pastagens destinadas à pecuária. Enquanto, as áreas de floresta, que se referem à vegetação arbórea de dossel contínuo, distribuem-se, timidamente, por toda bacia hidrográfica a montante do reservatório de Ernestina, tendo maior extensão na região centro-norte da área de estudo, mais especificadamente nos territórios de Marau, Passo Fundo e Ibirapuitã.

No que tange as áreas de solo exposto,estas são mais representativas nos territórios de Marau, Ernestina, ao sul de Ibirapuitã e Passo Fundo. Enquanto que as manchas urbanas destacam-se principalmente na porção sudoeste do município de Passo Fundo, e a sudeste do reservatório, pertence ao município de Nicolau Vergueiro.

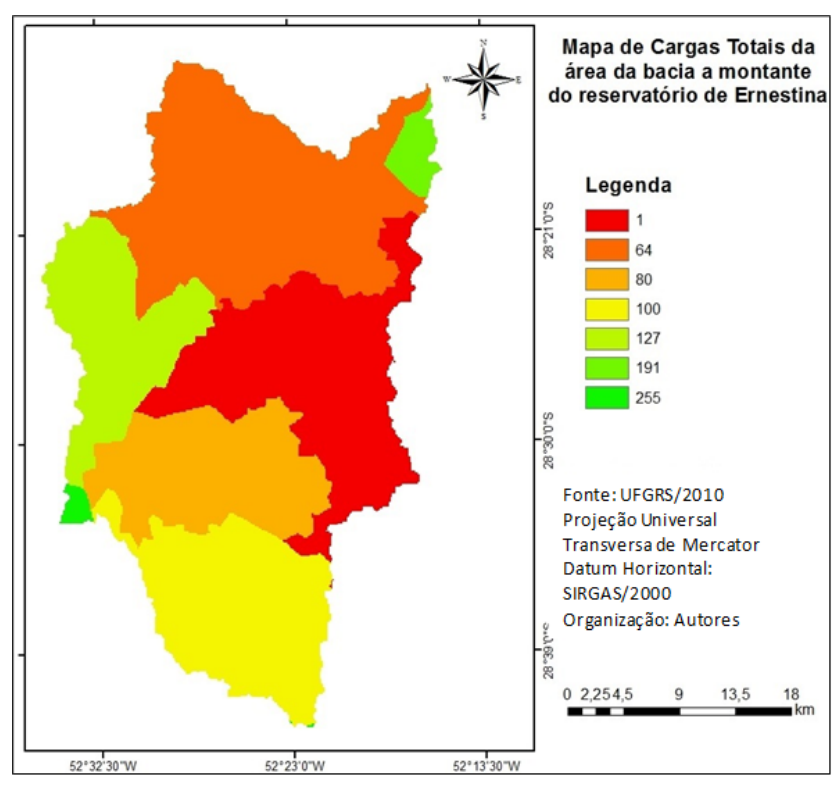

Figura 4 - Mapa de fragilidades do potencial de contaminação por cargas difusas e pontuais a montante do reservatório de Ernestina/RS Fonte: : Elaboração dos autores

\subsection{Variável potencial de cargas poluidoras ao re- servatório}

O mapa relativo ao potencial de contaminação orgânica por cargas pontuais e difusas da bacia a montante do reservatório de Ernestina (Figura 4) revela que a maior contribuição das cargas potencialmente poluidoras ao reservatório é proveniente do município de Marau, seguido por Passo Fundo, Nicolau Vergueiro, Ibirapuitã, Ernestina, Mato Castelhano e Tio Hugo.

As maiores cargas de $\mathrm{DBO}_{5}$ foram oriundas do município de Marau (superior a $20 \mathrm{t} \mathrm{d}^{-1}$ ) e Passo Fundo (10 a $20 \mathrm{t} \mathrm{d}^{-1}$ ), principalmente, pelo despejo de esgoto doméstico municipal, do último município, bem como fontes poluidoras licenciadas e despejos de origem animal em atividades agrossilvipastoris.

No que se refere aos nutrientes eutrofizantes analisados, observaram-se as maiores concentrações de $\mathrm{P}$ nos municípios de Marau (superior a $3 \mathrm{t} \mathrm{d}^{-1}$ ), Nicolau Vergueiro $\left(1\right.$ a $\left.3 \mathrm{t} \mathrm{d}^{-1}\right)$, Passo Fundo e Ibirapuitã $\left(0,5 \mathrm{a} 1 \mathrm{t} \mathrm{d}^{-1}\right)$ provindas de dejetos de origem animal, quando da aplicação de dejetos de fertilizantes agrícolas sobre o solo, descarte de esgotos municipais e de atividades agrossilvipastoris. Proveniente das mesmas fontes, as concentrações mais elevadas de NTK também foram observadas nos municípios de Marau (superior a $5 \mathrm{t} \mathrm{d}^{-1}$ ), Nicolau Vergueiro e Passo Fundo (2 a $\left.5 \mathrm{t} \mathrm{d}^{-1}\right)$ e Ibirapuitã $\left(1 \mathrm{a} 2 \mathrm{t} \mathrm{d}^{-1}\right)$.

Para os coliformes termotolerantes, o maior potencial de contaminação da água do reservatório de 
Ernestina é oriundo do município de Passo Fundo, que apresentou valores superiores a $2.000 .10^{12} \mathrm{UFC} \mathrm{d}^{-1}$ na área que drena para o reservatório. $\mathrm{O}$ município de Marau apresentou valores de contribuição de 1.000 a 2.000.10 ${ }^{12} \mathrm{UFC} \mathrm{d}^{-1}$ em relação à área de drenagem, seguido pelo município de Ibirapuitã, com contribuição de 500 a $1.000 .10^{12}$ UFC d $^{-1}$.

Com base no potencial de cargas poluidoras da região, ENGEPLUS (2012) estima que, até 2031, o trecho que compreende das nascentes até a barragem de Ernestina seja Classe 4 para os parâmetros coliformes termotolerantes, $\mathrm{DBO}_{5}$ e $\mathrm{P}$ e Classe 3 para nitrogênio amoniacal, independentemente da implantação de sistemas de tratamentos de esgotos nos municípios inseridos na bacia hidrográfica. Esta estimativa denota a fragilidade do reservatório quanto sua suscetibilidade à perda de qualidade da água em função das atividades desempenhadas na região.

\subsection{Variável resistência a impactos ambientais quan- to ao tipo de solo}

Com base no Sistema Brasileiro de Classificação de Solos, a bacia hidrográfica do reservatório de Ernestina é composta pelos solos LVd - Latossolos Vermelhos Distróficos, LVaf - Latossolos VermelhosAluminoférricos, NVdf - Nitossolos VermelhosDistroférricos, MTf - Chernossolos Argilúvicos Férricos e PVA a - Argissolos Vermelho-Amarelos Alumínicos (SANTOS et al., 2013).

Contudo, pelo mapa de solos do Estado do Rio

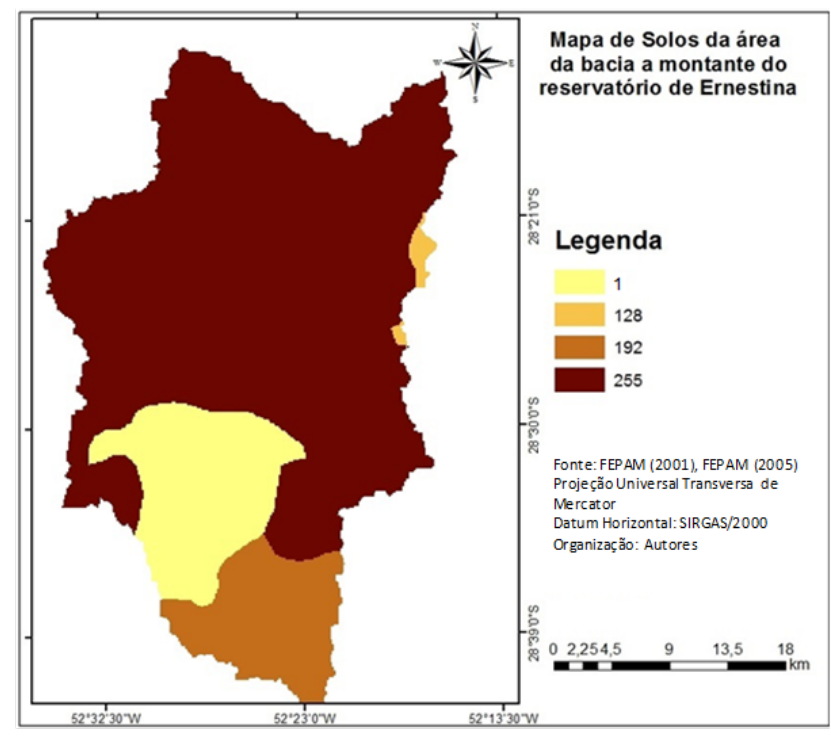

Figura 5 - Mapa de resistência à impactos ambientais quanto ao tipo de solo na bacia a montante do reservatório de Ernestina/RS Fonte: : Elaboração dos autores
Grande do Sul verifica-se predominância, na área de estudo, de Latossolo Vermelho distrófico húmico (LVd3), Latossolo Vermelhoaluminoférrico húmico (LVaf) e Nitossolo Vermelho distrófico típico (NVdf1) (STRECK et al., 2008). Estes solos, predominantes nos municípios de Ernestina, Passo Fundo e Marau, ao norte do barramento, apresentam alta resistência à impactos ambientais segundo FEPAM (2001), por caracterizarem-se como solos profundos, de textura argilosa, boa drenagem, baixa declividade, de relevo plano a suave ondulado e boa aptidão agrícola, com exceção de duas áreas do extremo leste da bacia que apresentam baixa resistência (Figura 5). Os solos destas duas áreas, a leste da bacia, possuem textura arenosa, drenagem imperfeita ou excessiva, lençol freático alto, forte erodibilidade e relevo forte ondulado.

As demais classes mencionadas, representativas da porção leste e sudeste do barramento, em Nicolau Vergueiro e Ibirapuitã, caracterizam-se por apresentar resistência média para impactos ambientais (Figura 5), ou seja, solos com forte ou acentuada drenagem, erodibilidade moderada a forte e relevo ondulado. Esta região ainda apresenta de boa a regular aptidão agrícola.

De acordo com o estudo realizado pela ENGEPLUS (2012), a estimativa de que a taxa média de produção de sedimentos através da perda de solo por erosão, calculada pela Equação Universal de Perda de Solo, seja de aproximadamente 48.250 t.ano $^{-1}$ de sedimentos que chegam aos cursos d'água, a montante do barramento na Bacia Hidrográfica do Alto Jacuí, considerando a taxa de entrega de sedimentos SDR1 e que, portanto, podem ser

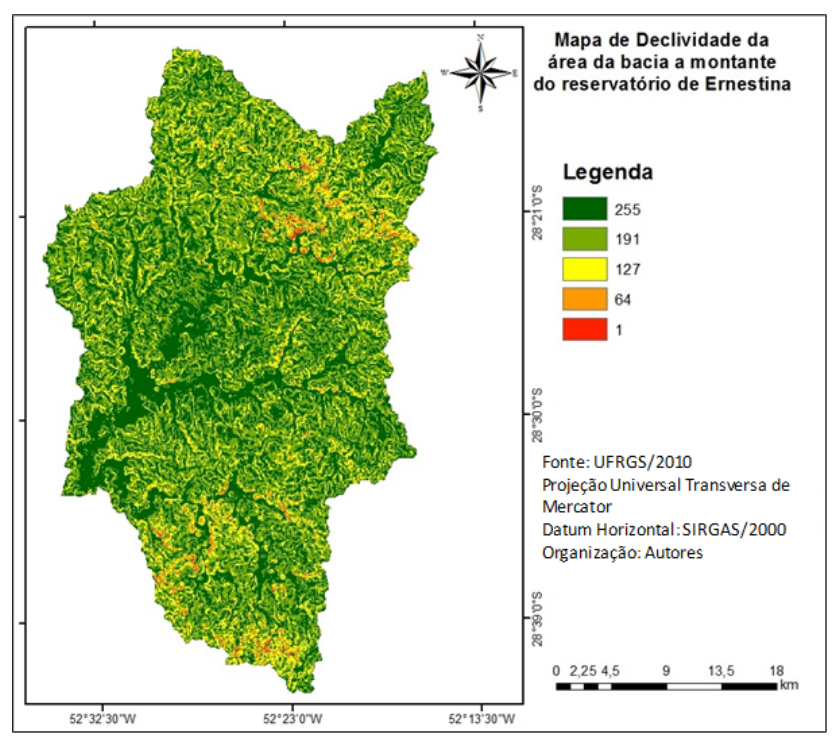

Figura 6 - Mapa de declividade da bacia a montante do reservatório de Ernestina/RS

Fonte: : Elaboração dos autores 
retidas no reservatório de Ernestina. Estes sedimentos podem reduzir a capacidade de armazenamento de água pelo reservatório e, consequentemente, afetar o potencial de geração de energia elétrica pelo empreendimento.

\subsection{Variável declividade}

Ao analisar o mapa de declividade da bacia hidrográfica a montante do reservatório de Ernestina (Figura 6), evidencia-se a predominância da declividade inferior a $20 \%$, onde a fragilidade do ambiente é classificada de média a muito fraca. No entanto, observa-se que alguns locais a declividade ultrapassam os 30\%, como, por exemplo, próximo à divisa entre os municípios de Passo Fundo e Marau e, também, nos municípios de Nicolau Vergueiro e Ibirapuitã. Nesses locais, a fragilidade ambiental passa a ser considerada como muito forte, contribuindo assim, consequentemente, para as elevadas concentrações e aporte de matéria orgânica e nutrientes para o reservatório. Essa situação é ratificada por meio dos resultados obtidos no mapa de cargas potencialmente poluidoras, os quais corroboram esta informação.

Contudo, ressalta-se a inexistência de áreas isoladas de baixa declividade. Por esse motivo, o uso da terra é fator determinante para a manutenção da qualidade da água do reservatório, seja pelo aporte de cargas ou carreamento de sedimentos para os recursos hídricos afluentes ao reservatório.

\subsection{Variável vulnerabilidade natural do aquífero à contaminação}

A área de estudo apresentou vulnerabilidade natural do aquífero à contaminação emtrês classes (Figura 7). Salienta-se o predomínio das classes de baixa e média fragilidade. Isso se justifica pelo fato do aquífero Formação Serra Geral estar protegido por uma camada confinante. Silva et al. (2013), por meio da aplicação do sistema GOD, encontraram, para o município de Erechim-RS (aquífero de Formação Serra Geral), predomínio das classes de média e baixa vulnerabilidade, como verificado neste estudo.

Uma pequena parcela da área de estudo apresentou alta fragilidade (Figura 7), tornando o aquífero mais vulnerável à contaminação. Um fator determinante para esse resultado pode ser o nível estático próximo da superfície, associado à condição livre e a falta de proteção por uma camada confinante. Esses pontos que apresentaram alta fragilidade estão localizados em áreas extremas do lago. Assim, pela pequena parcela a ser considerada, torna-se praticamente insignificante a alta fragilidade ambiental quanto à vulnerabilidade a contaminação do aquífero.

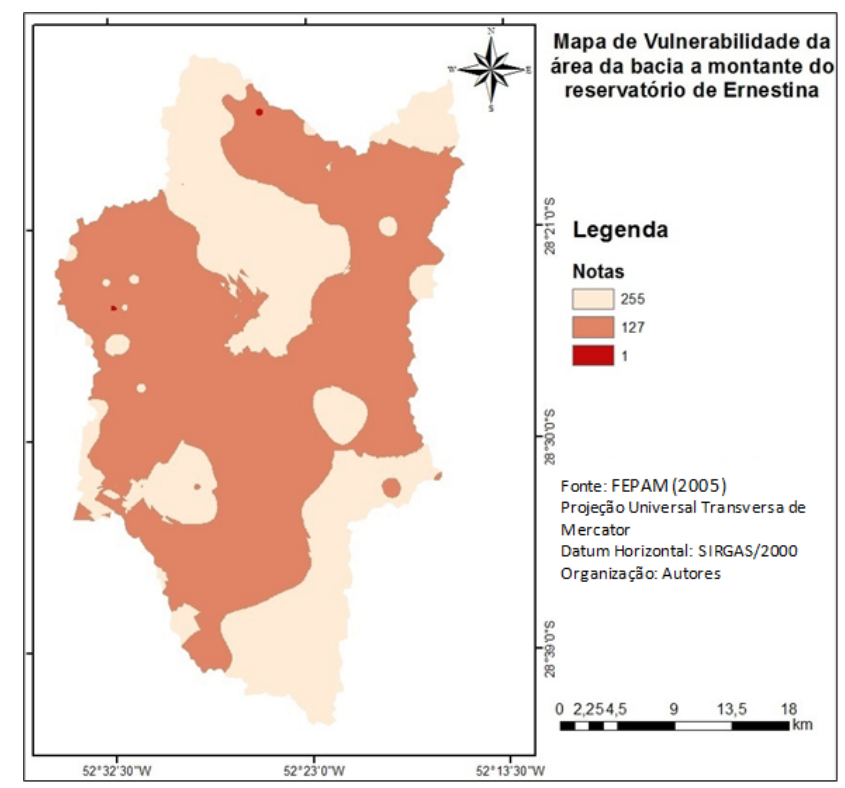

Figura 7 - Mapa de vulnerabilidade a contaminação da bacia hidrográfica do reservatório de Ernestina/RS Fonte: : Elaboração dos autores

\subsection{Mapa de fragilidade ambiental da bacia à mon- tante do reservatório de Ernestina}

Após a análise de fragilidade de cada variável isolada, estas foram combinadas para geração do mapa de fragilidade ambiental da bacia à montante do reservatório da UHE Ernestina/RS (Figura 8).

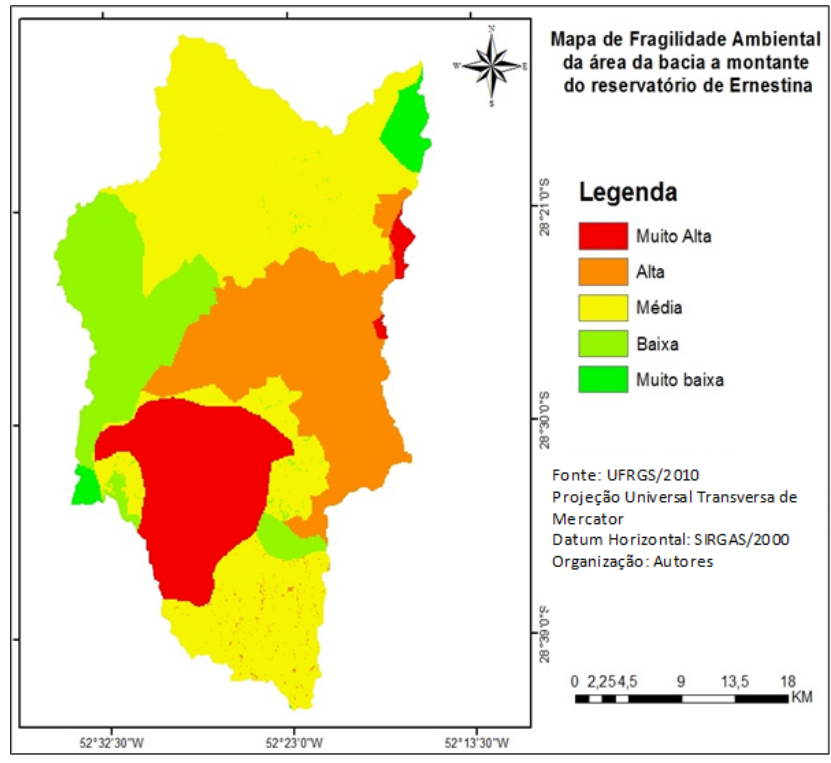

Figura 8 - Mapa de fragilidade ambiental da bacia a montante do reservatório de Ernestina/RS

Fonte: : Elaboração dos autores

Com base na Figura 8, observa-se que a fragilidade classificada como muito alta foi evidenciada, principalmente, 
em parte dos municípios de Nicolau Vergueiro e Ibirapuitã, o que pode ser atribuído aos tipos de solos do município que apresentam resistência média para impactos ambientais. Esta resistência se deve à acentuada drenagem e moderada erodibilidade com relevo de forte a moderado. Estes solos, combinados com declividade de 6 a 20\% e a predominância de lavouras, são responsáveis, também, pelo carreamento de matéria orgânica e nutrientes para o reservatório.

A região classificada como de alta fragilidade compreende parte do município de Nicolau Vergueiro e Marau, o que é atribuído, principalmente, pela elevada carga de matéria orgânica e nutrientes decorrentes da ocupação da terra por lavouras, presença de fontes poluidoras licenciadas, despejos de origem animal em atividades agrossilvipastoris e, ainda, despejo de esgoto doméstico municipal. Também, contribuiu para este resultado, a vulnerabilidade intermediária do aquífero à contaminação nessa região.

A fragilidade média observada no extremo norte da bacia do reservatório de Ernestina se deve ao despejo de esgoto doméstico de parte do município de Passo Fundo, em uma região com declividades mais elevadas. Também se observa, ao sul de Passo Fundo, ocupação de lavouras e fontes poluidoras licenciadas que contribuem para a classificação de fragilidade média da área. No que se refere à porção sul da bacia, a classificação de fragilidade média é decorrente da forte ocupação de lavouras e maior declividade, de 6 a 20\%, que é responsável pelo carreamento de cargas poluidoras ao reservatório. Novamente, a vulnerabilidade intermediária do aquífero, no noroeste de Ibirapuitã, pode ter contribuído para esta classificação. A fragilidade média foi a classificação com maior representatividade obtida na bacia.

Por fim, a região classificada como de baixa a muito baixa fragilidade caracteriza-se pela presença de lavouras, porém, de baixo potencial de contaminação de cargas. Isto pode ser explicado pelo solo de alta resistência a impactos ambientais nessas regiões, que não é afetado pela declividade de 12 a 20\% evidenciada em alguns locais e pelos limites de vulnerabilidade intermediária do aquífero à contaminação.

Um estudo similar realizado por Donhas et al. (2006) avaliaram a fragilidade ambiental de uma área no município de Pinhais, em Curitiba/PR, utilizando a técnica de avaliação por múltiplos critérios com mapas de declividade, distância dos rios, nascentes e represa, além do uso da terra. Foram atribuídos pesos de importância para cada um dos fatores com vistas a geração de imagens de fragilidade pela combinação linear ponderada. Desta forma, os autores observaram que as áreas de maior fragilidade estavam relacionadas às declividades mais acentuadas e a proximidade dos recursos hídricos, enquanto que as áreas de fragilidade mais baixa foram classificadas nas porções com menor declividade e mais distantes dos recursos hídricos.

\section{CONSIDERAÇÕES FINAIS}

Com base nos estudos realizados e na análise do produto final desta pesquisa, evidenciou-se que as áreas classificadas como de fragilidade muito baixa representam as menores porções territoriais da área de estudo e referem-se aos municípios com menor nível de perturbações na bacia hidrográfica em questão, como os municípios de Mato Castelhano e Tio Hugo.

Por outro lado, o cruzamento das variáveis permitiu identificar as regiões mais frágeis quanto à perda de qualidade da água, de redução da capacidade de armazenamento do reservatório e com potencial de influenciar a geração de energia elétrica pelo empreendimento. Estas áreas foram identificadas na porção leste e sudeste do reservatório, entre Nicolau Vergueiro, Ibirapuitã e Marau e que, portanto, devem ser priorizadas com ações mitigadoras para redução de impactos.

As variáveis declividade e vulnerabilidade do aquífero à contaminação, também contribuíram para a classificação de fragilidade muito alta para parte dos territórios de Nicolau Vergueiro e Ibirapuitã.

Assim, ratifica-se que o estudo de fragilidades ambientais da bacia hidrográfica à montante do reservatório de Ernestina pode ser considerado excelente ferramenta para diagnóstico das perturbações, tanto para o empreendimento, quanto para os municípios e o comitê de bacia hidrográfica envolvido, por meio do planejamento e gestão. Contribuindo, assim, para manutenção e prolongamento da operação da UHE de Ernestina.

\section{REFERÊNCIAS}

AGÊNCIA NACIONAL DE ENERGIA ELÉTRICA ANNEL. Capacidade de Geração do Brasil. Banco de Informações de Geração. 2017. Disponível em: http:// www.aneel.gov.br/aplicacoes/capacidadebrasil/capacidadebrasil.cfm. Acesso em: 24 jan. 2018. 
BRASIL. Resolução CONAMA n ${ }^{\circ}$ 01, de 23 de janeiro de 1986. Dispõe sobre critérios básicos e diretrizes gerais para o Relatório de Impacto Ambiental - RIMA. Disponívelem: http://www.mma.gov.br/port/conama/ legiabre.cfm?codlegi=23. Acesso em: 04 jan. 2016.

BRASIL. Ministério do Meio Ambiente. Projeto Frag-Rio. Relatório Etapa 1. Desenvolvimento metodológico e tecnológico para avaliação ambiental integrada aplicada ao processo de análise de viabilidade de hidrelétricas. São Gabriel, RS: UNIPAMPA/UFSM, 2010. 296 p.

CAVALCANTI, L. C. S. Cartografia de Paisagens: fundamentos. São Paulo: Oficina de Textos, 2014.

COMPANHIA DE PESQUISA DE RECURSOS MINERAIS - CPRM. 2005. Mapa Hidrogeológico do Rio Grande do Sul. Disponível em: http://www.cprm. gov.br. Acesso em: 15 jan. 2016.

COMPANHIA DE PESQUISA DE RECURSOS MINERAIS - CPRM. Mapa Geológico do Estado do Rio Grande do Sul. Brasília: CPRM, 2007. Escala 1:750.000.

DONHA, A. G.; SOUZA, L. C. P.; SUGAMOSTO, M. L. Determinação da fragilidade ambiental utilizando técnicas de suporte à decisão e SIG. Revista Brasileira de Engenharia Agrícola e Ambiental, v.10, n.1, p.175181, 2006.

ENGENHARIA E CONSULTORIA LTDA - ENGEPLUS. Relatório Síntese do Planejamento dos Usos da Água na Bacia Hidrográfica do Alto Jacuí - Etapas A e B. Aprovador Fernando Fagundes. Porto Alegre, RS. 2012. 144 p.

FUNDAÇÃO ESTADUAL DE PROTEÇÃO AMBIENTAL HENRIQUE LUIZ ROESSLER - FEPAM. 2005. Base cartográfica digital do RS. 1:250.000, 2005.

FUNDAÇÃO ESTADUAL DE PROTEÇÃO AMBIENTAL HENRIQUE LUISROESSLER - FEPAM. Mapa de Classificação dos Solos do Estado do Rio Grande do Sul quanto à Resistência a Impactos Ambientais. Porto Alegre: FEPAM. 13 p. (n. publ.) Relatório final de consultoria elaborado por Nestor Kämpf. Mapa em meio digital. 2001.
FOSTER, S. et al. Proteção da Qualidade da Água Sub $\neg$ terrânea: um guia para empresas de abastecimento de água, órgãos municipais e agências ambientais. Ground-water Management Advisory Team (GW.MATE WB). Edição brasileira. São Paulo: Servmar, 2006.

GHEZZI, A. O. Avaliação e mapeamento da fragilidade ambiental da Bacia do Rio Xaxim, Bahia de Antonina - PR, com o auxílio de geoprocessamento. 2003. 64p. Dissertação (Mestrado em Ciência do Solo) Universidade Federal do Paraná, Curitiba.

HASENACK, H.; WEBER, E. (Org.). Base cartográfica vetorial contínua do Rio Grande do Sul. Porto Alegre: UFRGS Centro de Ecologia. 2010. 1 DVD-ROM. (Série Geoprocessamento n. 3). Escala 1:50.000.

MELO, F. P. de. Risco Ambiental e Ordenamento do Território em Garanhuns - PE. 2016. 247p. Tese (Doutorado em Geografia) - Universidade Federal do Sergipe, São Cristovão.

MELO, F. P. de et al. Estimativa de Precipitação em Segmentos de Bacias Hidrográficas subsidiado pelo Método de Thiessen em Ambiente de SIG. In: SIMPÓSIO SOBRE AS GEOTECNOLOGIAS E GEOINFORMAÇÃO NO ESTADO DE ALAGOAS. 4., 2016, Maceió. Publicação online...Maceió: $4^{\circ}$ GEO ALAGOAS, 2016. 7 p.

PADILHA, G., D. Geoprocessamento Aplicado na caracterização da fragilidade ambiental da Bacia Hidrográfica do Arroio Grande - RS. 2008. 87p. Dissertação (Mestrado em Geomática). Universidade Federal de Santa Maria, Santa Maria.

ROSS, J. L. S. Análise empírica da fragilidade dos ambientes naturais e antropizados. Revista do Departamento de Geografia, v.8, p. 63-74, 1994.

SANTOS, H. G. dos et al. Sistema Brasileiro de Classificação de Solos. 3. ed. Brasília: EMBRAPA, 2013.

SILVA, J. L. S.da et al. Vulnerabilidade do aquífero Serra Geral à contaminação no município de Erechim - Rio Grande do Sul - Brasil. Ciência e Natura, v.35, n.1, p. 10-23, 2013. 
SISTEMA DE INFORMAÇÕES DE ÁGUAS SUBTERRÂNEAS -SIAGAS.Serviço Geológico do Brasil. Disponível em: http://siagasweb.cprm.gov.br/layout/. Acesso em: 20 nov. 2015.

STRECK, E. V. et al. Solos do Rio Grande do Sul. 2. ed. Porto Alegre: EMATER/RS, 2008.

TAMIOSSO, C. F. Análise de Fragilidades Ambientais aplicada à Gestão da Qualidade das Águas: Estudo de caso da Bacia do Rio Santa Maria, RS. 2011. 138p. Dissertação (Mestrado em Engenharia Civil)- Universidade Federal de Santa Maria, Santa Maria.

TAVARES, R. Construindo mapas conceituais. Ciências \& Cognição, v.12, p. 72-85, 2007.

\title{
Correspondência dos autores:
}

\author{
Ramiro Pereira Bisognin \\ e-mail: ramirobisognin@yahoo.com.br
}

Patrícia Ziani

e-mail: pathyziani@hotmail.com

Carine Baggiotto

e-mail: carine.bg@hotmail.com

Gabriel Fernandes

e-mail: enggabrielfernandes@gmail.com

Rafael Cabral Cruz

e-mail: rafaelcabralcruz@gmail.com

Artigo recebido em: 18/09/2017

Revisado pelos autores em: 27/12/2017

Aceito para publicação em: 25/01/2018 